Article

\title{
Fire Protection of Building Constructions with the Use of Fire-Retardant Intumescent Compositions
}

\author{
Tatiana Eremina * (1) and Dmitry Korolchenko \\ Department of Integrated Safety in Construction, Moscow State University of Civil Engineering, 26, \\ Yaroslavskoye Shosse, 129337 Moscow, Russia; ICA_kbs@mgsu.ru \\ * Correspondence: main@stopfire.ru
}

Received: 9 September 2020; Accepted: 12 October 2020; Published: 15 October 2020

check for updates

\begin{abstract}
The influence of basic components of intumescent paint on fire protection properties is studied. The resulting changes in properties are assessed by the intumescence coefficient and thermal analysis data. Influence of the binder polymer composition on fire protection properties under the same conditions was evaluated, quantitatively using the example of fire-retardant water-dispersion paint; the best result was obtained in the formulation based on vinyl acetate copolymers. The brands of ammonium polyphosphate (PFA) from different manufacturers were investigated under the same conditions. The results of the thermal analysis and testing of the physicochemical properties of the samples on various PFAs are presented, with conclusions about their influence on the fire-retardant properties of the paint. The results of the thermal analysis of the influence of orthophosphoric acid, as a modifying additive, on the fire-retardant properties of the paint are presented.
\end{abstract}

Keywords: fire protection properties; fire resistance limit; fire protection intumescent paint; binders; antipyrenes; foam intumescence ratio

\section{Introduction}

In recent years, large multifunctional and high-rise buildings and complexes have been under construction in many cities. These multifunctional buildings include groups of premises for different functional purposes (residential, administrative, office, cultural and entertainment, healthcare, parking, etc.). One of the most important aspects in fire safety analysis is an investigation of the real fire resistance limit for building constructions according to the following requirement:

$$
\mathrm{R}_{\mathrm{f}}>\mathrm{R}_{\mathrm{req}} \text {, }
$$

where $\mathrm{R}_{\mathrm{f}}$-real fire resistance limit; and $\mathrm{R}_{\mathrm{req}}$-required fire resistance limit.

A prospective direction in the investigation of fire resistance of building constructions covered with fire-retardant intumescent paints is the analysis of their behavior at high temperatures. Thus, the influence of physical and chemical processes on fire-retardant properties has been investigated worldwide.

Nowadays, we choose the optimal fire-retardant composition, taking into account the specifics of the facility maintenance and the results of the fire tests with a standard temperature regime (Figure 1). 


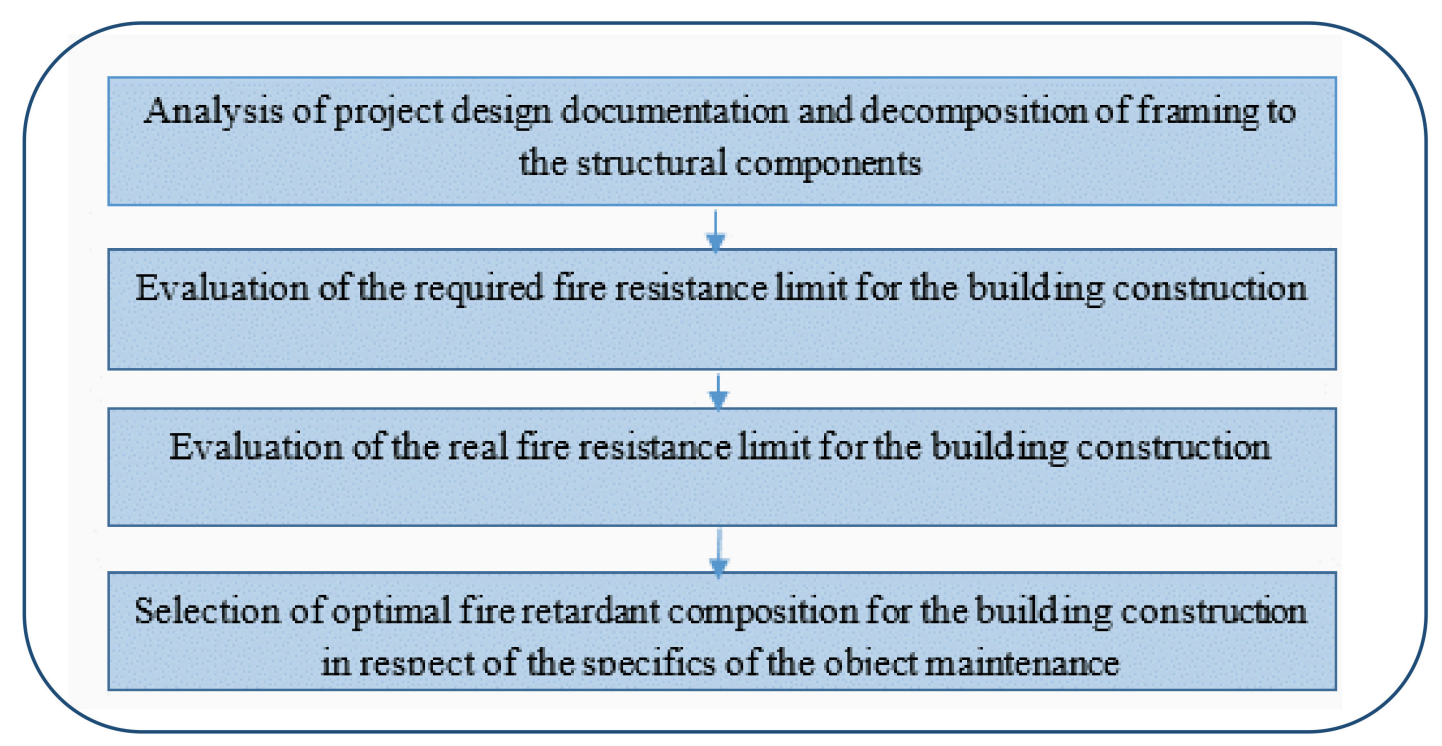

Figure 1. The algorithm of selection of the optimal fire-retardant composition.

The influence of physical and chemical processes on the fire-retardant properties at high temperature is investigated to select the optimal fire-retardant composition for building constructions with respect to the specifics of the facility maintenance. One of the criteria for selection of intumescent fire-retardant paint is the required fire resistance limit for the building elements. Fire resistance evaluation is based on experimental data for similar constructions or experimental data for intumescent fire-retardant paints.

The results of the certified and additional tests are documented in the tables (nomograms). They present the minimal thickness of the fire-retardant coating, which is necessary to achieve the required fire resistance limit, depending on the effective thickness of the metal and on the critical temperature value obtained from the static calculations.

The effective thickness of the metal and the critical temperature value are not enough to determine the thickness of the intumescent fire-retardant coating. Firstly, the calculated thickness of the intumescent coating is based on the standard conditions of the certified tests, particularly on the results of a standard temperature regime according to the prescriptive approach in design. Then, the results of the standard tests are applied to all temperature regimes without detailed investigation of their influence on the intumescent fire-retardant coating's behavior. Such an assumption in fire resistance design for steel constructions presents stability for the heat engineering properties of the intumescent coatings for various conditions of a temperature regime. However, intumescent coatings are chemically active compositions and their heat engineering properties depend not only on temperature, but on the heating conditions and fire exposure type as well.

One of the most effective ways to protect steel structures in case of fire are thin-layer polymer coatings, which can increase many times when heated. The intumescent coverings are composite materials, including a polymeric binder and fillers (intumescent system, inert fillers, and stabilizers of the foamed coal layer). During bloating and simultaneous charring, a fine-meshed layer with low thermal conductivity is formed, as a result of which the heating of the constructions slows down sharply. Each component of the intumescent formulation should be carefully selected, followed by an assessment of its effect on fire protection properties. On the basis of the theoretical and experimental studies of fire-protective swelling coatings, the main types of mandatory ingredients of this type of compound can be identified. The ingredients of the compositions are classified in accordance with the functional contribution of each of them to the process of thermolytic synthesis of fire-retardant coatings. The ingredients include donors of acid (ammonium phosphates), coking agents (pentaerythritol, cellulose, starch, and dextrin), porophorax (melamine, urea, guanidine, and chloroparaffins), and a 
polymer binder [1-3]. It is known that an important part of the formulation of the fire protection intumescent coating is a binder (resin or film-forming agent). The main function of a binder is to ensure quality adhesion to the substrate, elasticity, hardness, durability, and operating conditions. Taken together, the above physical and chemical characteristics allow to obtain a high-quality, defect-free, durable fireproof coating and have a direct impact on the fireproof properties [4]. Therefore, one of the topical issues is the study of the properties of the binder. Depending on the area of application or the desired type of paint, natural substances are used as a binder, either synthetic or modified in different ways. Binders are solid or liquid polymers that dissolve or disperse in a solvent or water. As the binder dries, a paint film is formed. The drying process can be physical or chemical. Typically, the binder is dried and polymerized in a mixed process. The physical process refers to the drying of the binder without a chemical reaction, e.g., as a result of the evaporation of solvents. In the case of chemical drying, hardening is achieved by a chemical reaction. The coating can be formed, for example, by oxygen in the air or by a reaction with a hardener. The main types of binders used in fire protection intumescent coatings are PVAD (polyvinyl acetate dispersion), liquid glass, acrylic dispersion, acrylic resins, acrylic copolymers, rubber, epoxy, perchlorovinyl, and silicone resins. Numerous standard studies are described in the literature, where the influence of the nature of the binder and its work at a certain ratio of antipyrenes on the final properties of the coating is considered [1-6].

The main and actually irreplaceable ingredients of fire protection intumescent compositions are the following fire retardants: ammonium polyphosphate, melamine, and pentaerythrite in a ratio of 3:1:1. Pentaerythrite (2,2-di-(oxymethyl)1,3-propanediol) in most cases acts as the main hydroxyl-containing component in fire protection intumescent compositions. Melamine (2,4,6-triamino-1,3,5-thriazine) is a colorless, odorless crystal. This compound belongs to the class of cyclic cyanamides and has a set of properties that are a result of the energy stability of triazine nuclei. These properties include heat, light, and chemical resistance, as well as the ability to form polyfunctional reactive chemical compounds. The melamine melting point is clearly indicated by the endothermic peak at $340^{\circ} \mathrm{C}$. After melting in the temperature range of $350-430{ }^{\circ} \mathrm{C}$, melamine transforms into melem, and at $430-500{ }^{\circ} \mathrm{C}$ melem transforms into melon. Melon is resistant to heating up to $740^{\circ} \mathrm{C}$. Thus, melamine and products of its transformation are long lasting and, therefore, can react with aldehydes, forming melaminoaldehyde oligomers. A high temperature during synthesis, naturally, should dispose to the formation of spatially cross-linked structures-melaminoaldehyde resins of complex composition. Similar processes are likely to take place in the intumescent systems, where instead of melamine, urea or dicyandiamide is used. Ammonium polyphosphate (PFA) is a dehydrating agent and catalyst for curing the resulting foamcoke structure. Ammonium polyphosphate is the main antipyrene in the fire protection paint; its share can reach $25 \%$ of the total composition. Ammonium polyphosphate is an inorganic polymer of a branched structure-ammonium salt of polyphosphoric acid, fine white powder, incombustible, non-toxic, and poorly soluble in water. When heating PFA to temperatures of about $250-280{ }^{\circ} \mathrm{C}$ (depending on the degree of polymerization), endothermic decomposition with formation of polyphosphoric acid and release of ammonia occurs [7-10].

\section{Metodology}

The most commonly used binders in intumescent, waterborne, fire protection paints are copolymers based on vinyl acetate and their modifications and some types of copolymer-acrylic binders. Table 1 presents test data for several types of binders and measurement of the intumescent coefficient as a criterion for intumescence properties. The tests were carried out using PFA (ammonium polyphosphate) fire retardants, melamine, pentaerythritol in the ratio of 3:1:1, and several types of binders based on the fireproof paint formulation test. The intumescent coefficient and the time when the samples achieve the limiting condition at $500{ }^{\circ} \mathrm{C}$ in a standard heating mode have been defined. The research results showed that, at the same antipyrene ratio, the intumescent coefficient and time to reach the limiting state depend on the chemical nature of the binder used. The time taken by a sample to reach the limit 
state according to this criterion of fire resistance is considered to be the time (in minutes) that has passed from the beginning of the test to the first sign of the limit state according to the given criterion. Figure 2 shows the graphical dependence of the four average values of the coatings, from which it is seen that there is a change in the temperature over time depending on the type of binder.

Table 1. The intumescent coefficient and time to reach the limit state of specimens of different binders.

\begin{tabular}{cccc}
\hline No & Type of Binder & Intumescent Coefficient, $\mathbf{k}$ & $\begin{array}{c}\text { Time for Reaching } \\
\text { Limit Condition, min }\end{array}$ \\
\hline 1 & $\begin{array}{c}\text { Polyvinyl acetate-based dispersion } \\
\text { Highly dispersive vinyl acetate copolymer } \\
\text { with ethylene vinyl chloride }\end{array}$ & 56 & 65 \\
3 & $\begin{array}{c}\text { Highly dispersive vinyl acetate copolymer } \\
\text { with ethylene }\end{array}$ & 42 & 56 \\
4 & Highly dispersive vinyl acetate copolymer & 41 & 69 \\
with vinyl versatate & 52 & 39 \\
6 & Styrene-acrylate dispersion & & 51 \\
\hline
\end{tabular}

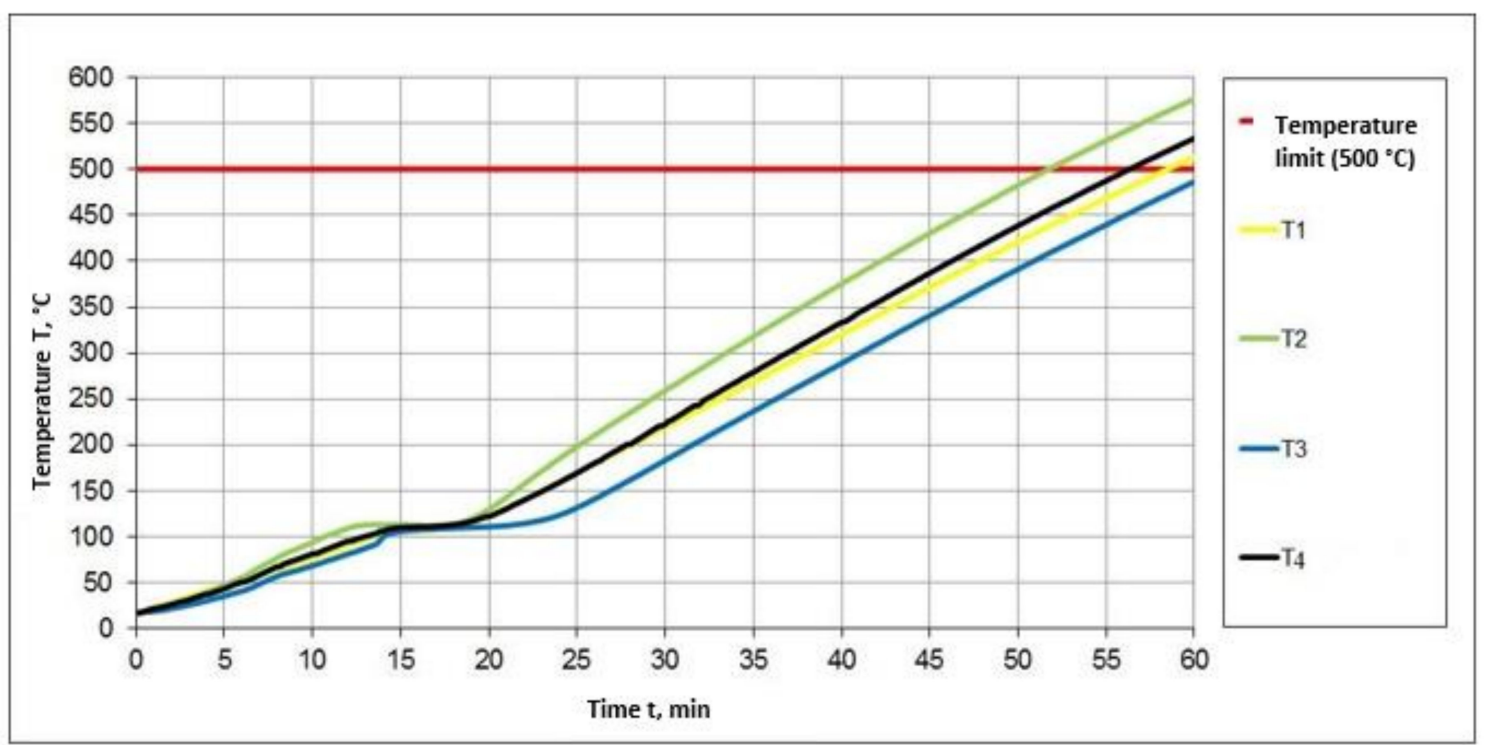

Figure 2. Timeline for the temperature extremes of the paint samples for the various binders. T1—sample No. 1; T2—sample No. 2; T3—sample No. 3; T4—sample No. 6.

The fireproof paint tests on different types of binders have shown that the acrylate-based film-formers are inferior to the vinyl acetate copolymers and their modifications considered in this particular formulation. The conducted tests show the necessity for detailed consideration of the polymers used as binders in the intumescent system, as they work in combination with certain fire retardants and other components of the formulation and, therefore, depending on the selected composition, the test results change.

Consider the impact of the physical and chemical properties of the intumescent coating on its fire protection properties on the example of the test paint. The tested fireproof paint is a composition of fire retardants, with a binder on the basis of polyvinyl acetate and modifying additives. Raw components of fire-retardant materials are widely represented in the market by a variety of manufacturers and suppliers and are readily available. At the same time, however, the quality characteristics of seemingly the same chemicals often differ. Comparative thermal studies of different brands of PFA (Figures 2-5) presented on the raw materials market have been conducted. PFA exist in two types: with crystal phase I (degree of polymerization $n<1000)$ and crystal phase II $(n>1000)$. The first type is characterized by 
a linear structure, lower decomposition temperature, and high degree of water solubility; so, in the production of fire protection paints, a phase II polyphosphate with a high degree of polymerization is used. Ten PFA samples from the different manufacturers present in the market were chosen for the investigation.

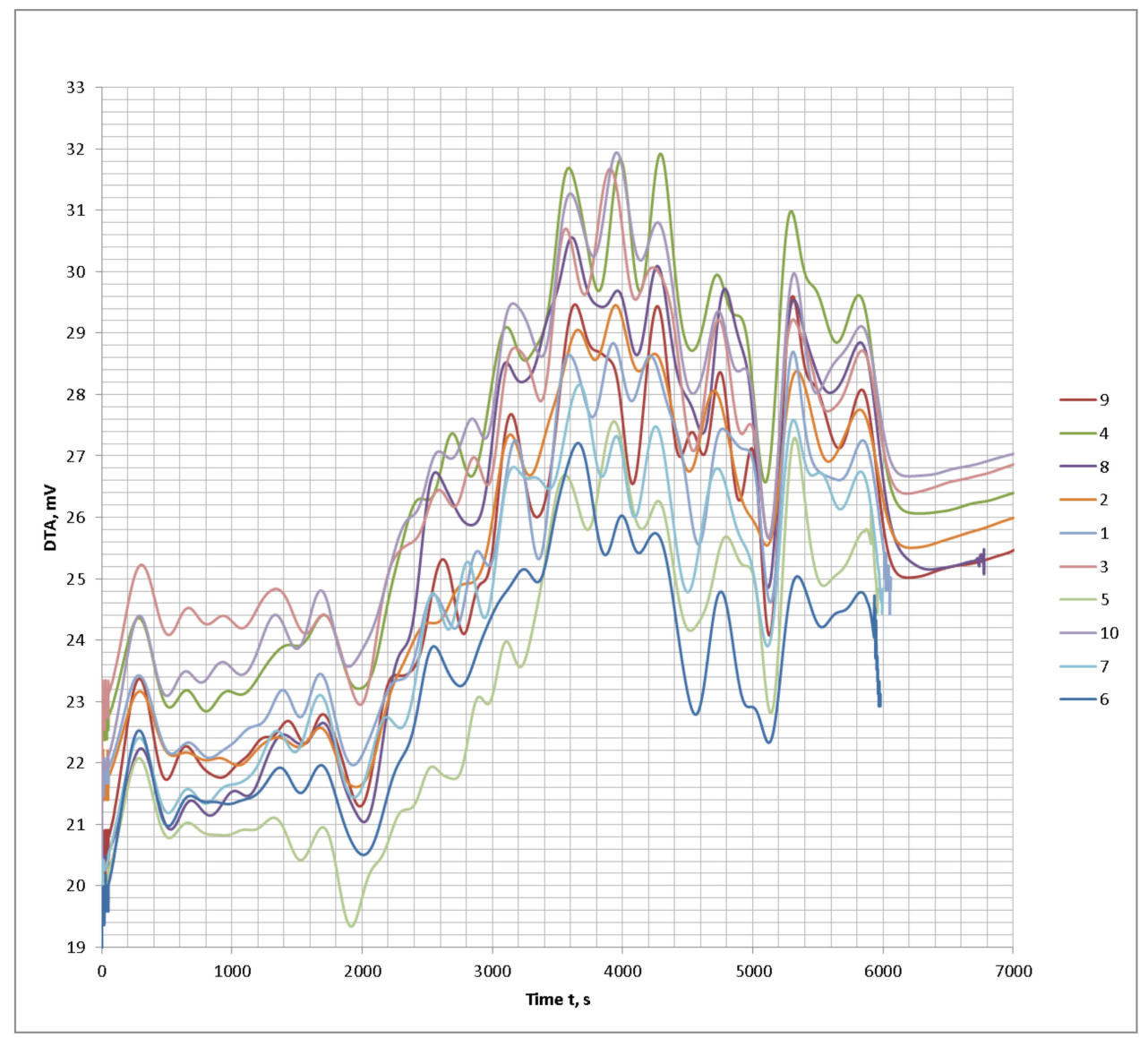

Figure 3. DTA thermograms of the tested ammonium polyphosphate (PFA) samples of the different brands.

Based on the graphical data of the thermal analysis of the different brands of PFA with conditionally similar characteristics, it can be concluded that the visible differences in some brands will also affect the general formulation of the composition upon interaction with the other components and have an impact on the fire protection properties.

In Table 2, the data of the laboratory research of the physical and chemical indicators on the example of the tested fireproof paint with the use of different brands of PFA in the formulation are presented. In this study, the estimation of the intumescent coefficient of the composition as a parameter of the evaluation of the intumescent properties of the system was made. Samples of paints according to a standard formulation were produced for conducting research in laboratory conditions. All components of the formulation were taken from the same batch of raw materials and in the same quantities, with differences only in the brand of PFA used. 


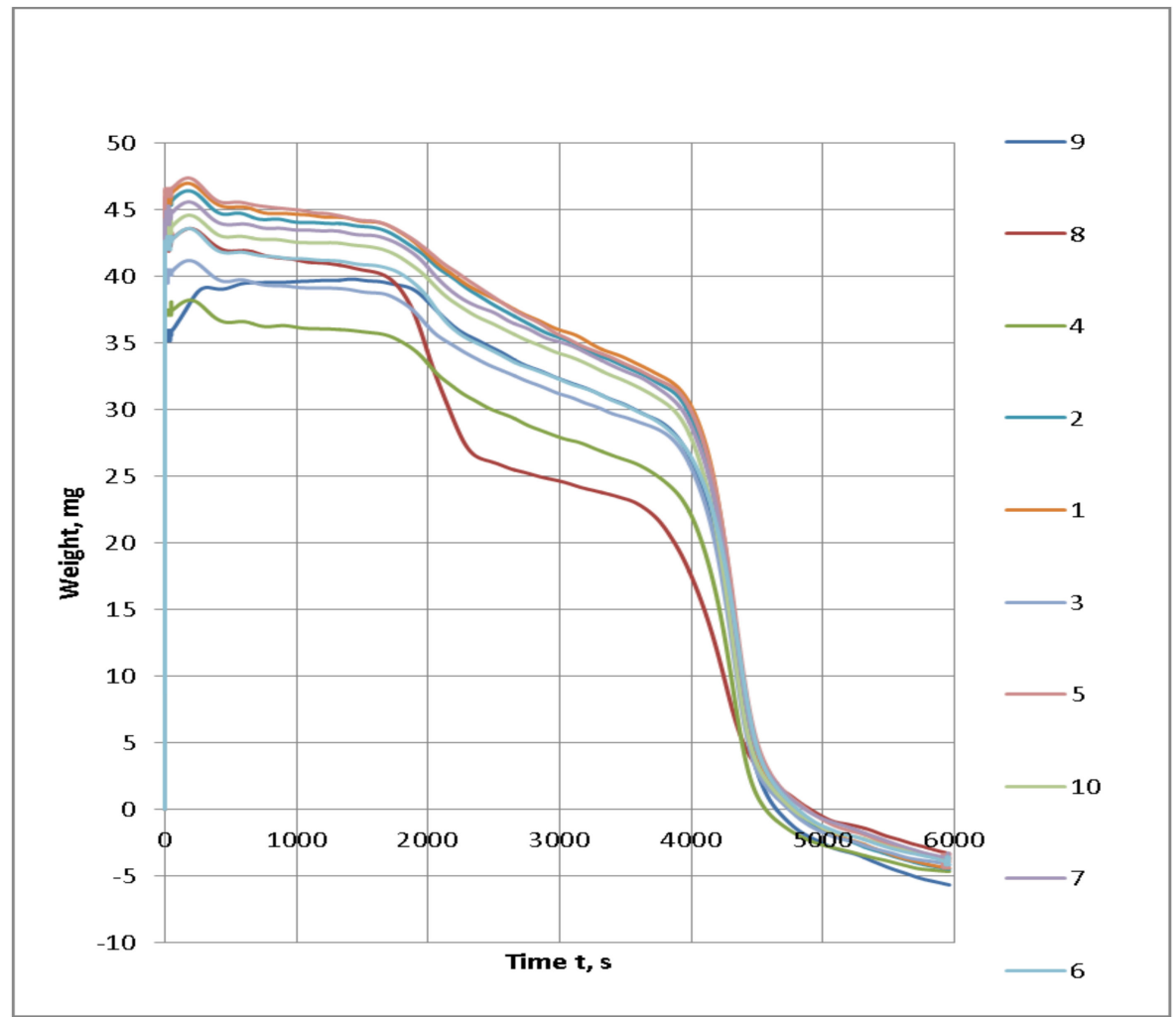

Figure 4. TG thermograms of the tested PFA samples of the different brands.

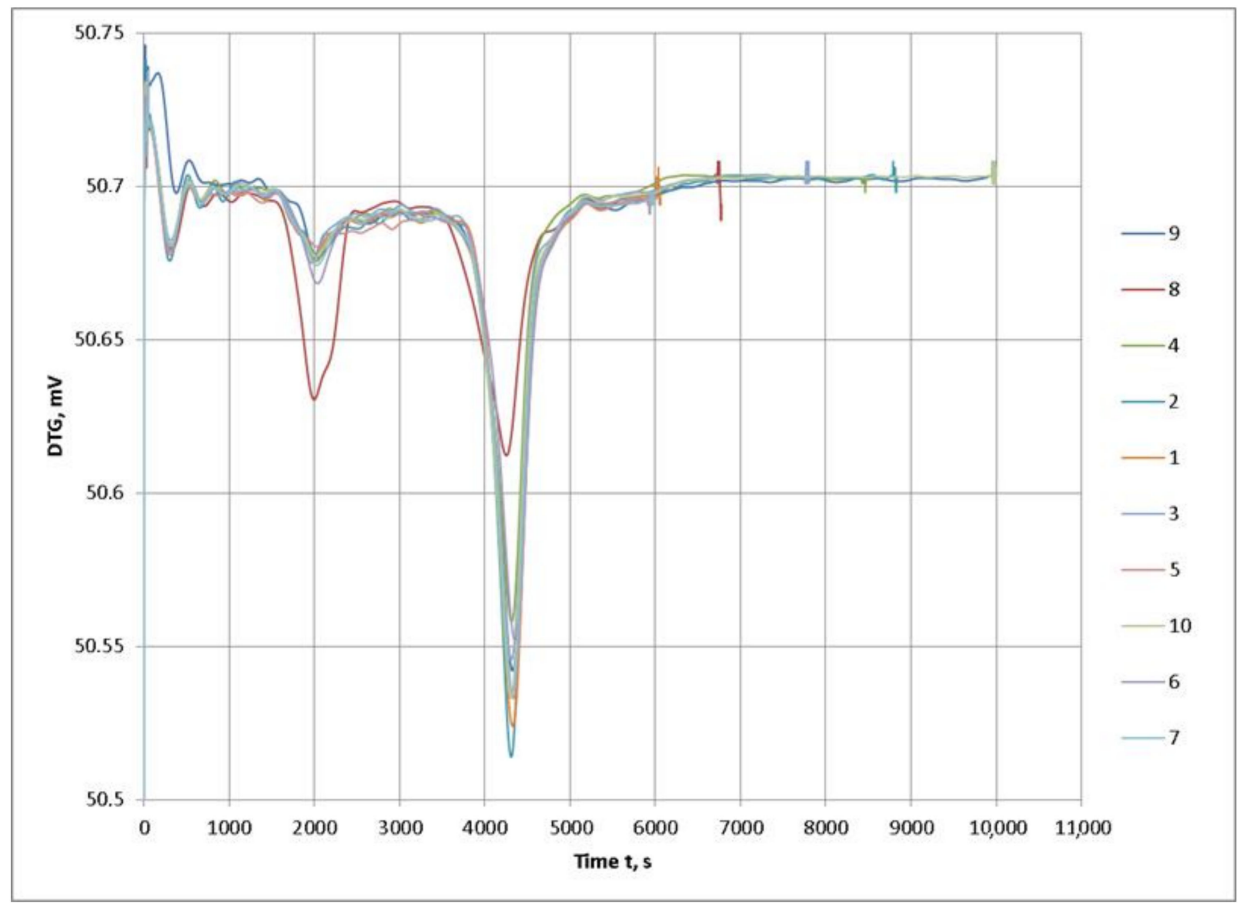

Figure 5. DTG thermograms of the examined PFA samples of the different brands. 
Table 2. Generalized structure of the tested fireproof paint formulation.

\begin{tabular}{ccc}
\hline No & Name & \% Mass \\
\hline 1 & Polyvinyl acetate-based dispersion & 23 \\
2 & Antipyrene combination: PFA, Melamine, Pentaerythrite & $38(3: 1: 1$ acc.) \\
3 & Modifying additives (dispersant, thickener, foam & 3 \\
4 & extinguisher, and SAW) & 14 \\
5 & Fillers of various nature & 20 \\
\hline
\end{tabular}

Based on the analysis of the tested fireproof paint's coating, it can be concluded that the various PFA brands used do not affect the physical and chemical properties of the paint as a whole (all samples have formed a strong homogeneous coating with good adhesion to the substrate). Thermal tests of the coating samples to determine the intumescent coefficient showed that, with the same component formulations, the use of different brands of PFA affects the intumescent coefficient and the quality of the formed foamcoke. Samples 3, 4, and 6 had a lower intumescent coefficient compared to the others. Samples 3, 4, and 6 had coarse foamcoke and were not suitable for use in the tested fireproof paint. Thus, it can be concluded that the study of the influence of the antipyrene brand on the complex physical and chemical properties of the composition in a specific paint formulation is an important and integral part of the program of development and evaluation of fire protection properties [11-18].

The foam crusts No. 9 and No. 10 are shown in Figure 6. Sample 9 is characterized by a low intumescent coefficient-42. The heat-insulating layer of Sample 10 is more stable and denser, with an intumescent coefficient of 67 .

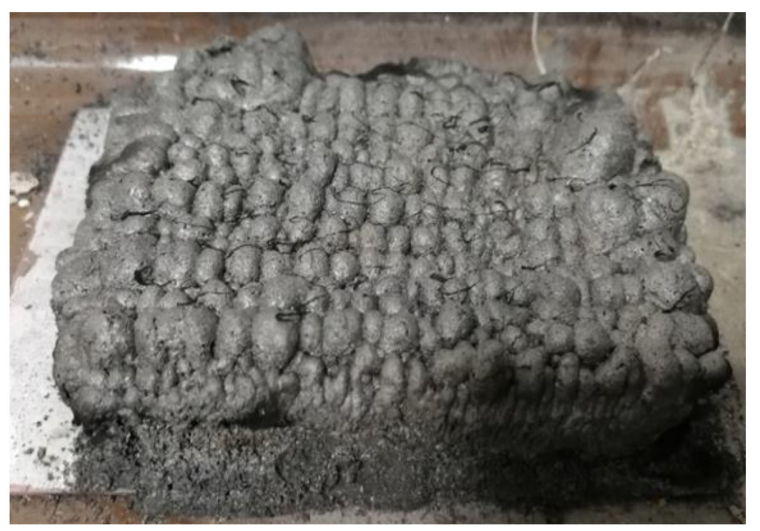

(a)

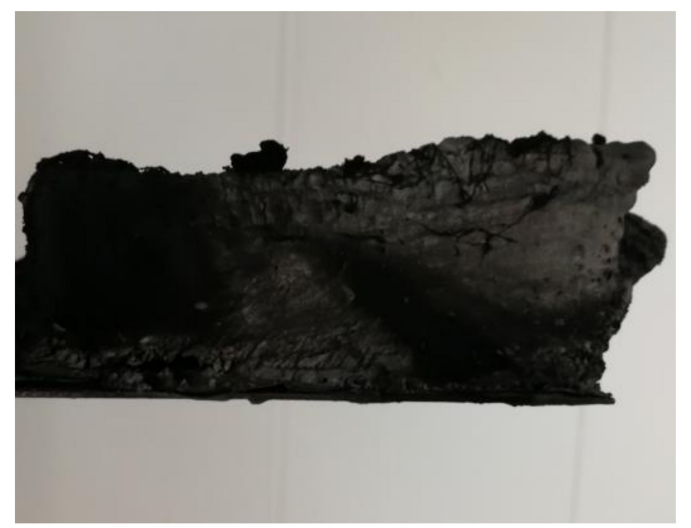

(b)

Figure 6. The foamy crust of the samples: (a) the foamy crust of Sample 9; (b) the foamy crust of Sample 10.

Sample No. 10, as the best variant, was used in large-scale fire tests for fire resistance effectiveness in accordance with GOST 53295-2009 [19]. The tests were performed in a steel column (section factor 3, 4) in the fire standard curve mode. Time for the limit state of $500^{\circ} \mathrm{C}$ of the sample was registered in the tests (Figure 7). The time is equal to $65 \mathrm{~min}$, corresponding the 4th group of fire resistance.

It is widely known that each component of the formulation of the intumescent fire-protective composition can have an indirect effect on the fire protection properties, and at the same time it can be used to modify other parameters of the formulation.

Fire protection paints, like other types of paint materials, tend to form coatings with visible external defects. Such defects may include cracks, uneven surfaces, punctures, craters, etc. Consider solving the cratering problem by one of the methods using the tested fireproof paint as an example. Cratering defects can be caused by many factors: substrate and coating incompatibility, incompatible 
or mismatched components and their quality, accidental air capture during the technological process, operator's skill, application technology, and substrate inhomogeneity. In most cases, cratering can be caused by the difference in phase tension between the coating and the substrate. In the tested water-based fire protection paint, crater formation may occur, apart from the above reasons, due to the release of ammonia, which is formed by the dissociation of ammonium polyphosphate.

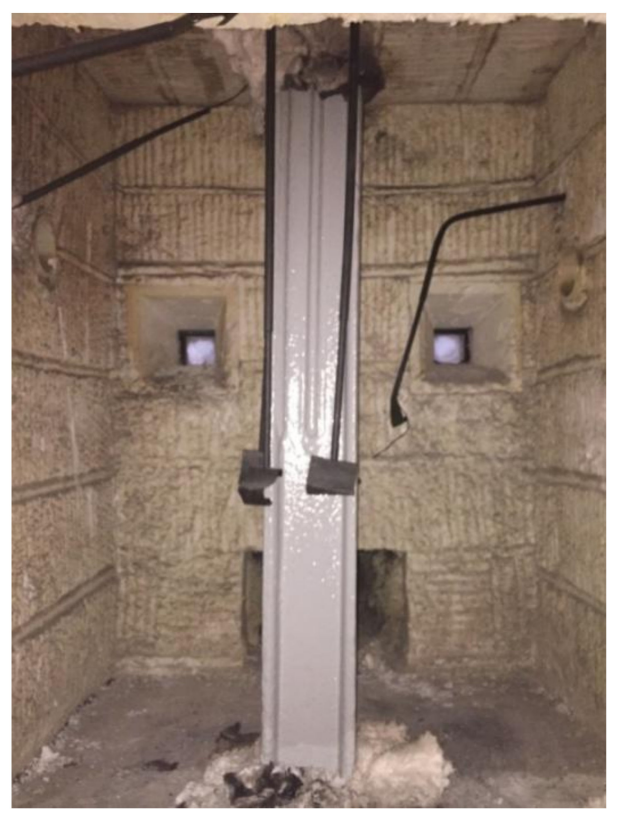

(a)

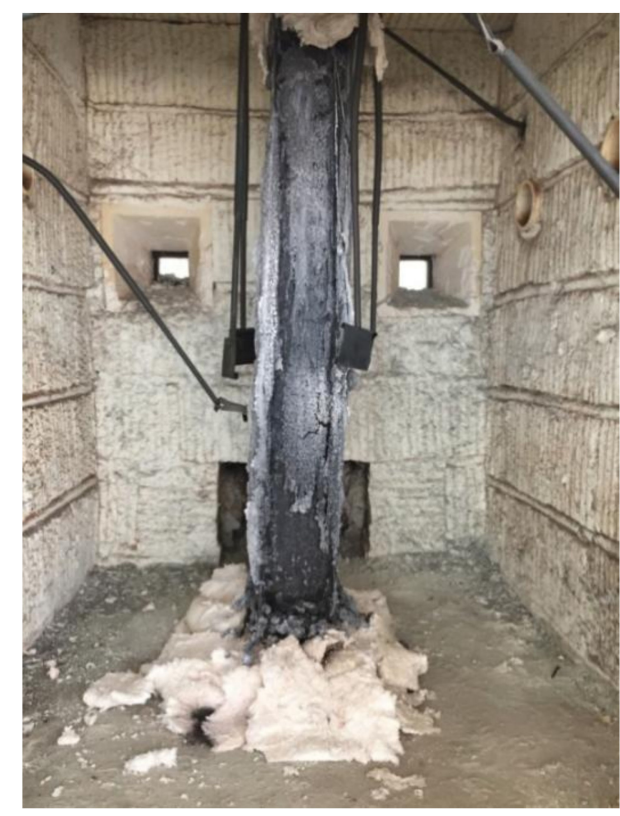

(b)

Figure 7. The external appearance of the coatings for Specimen 10: (a) before the tests; (b) after the tests.

As a solution to the problem of cratering due to the decomposition of ammonium polyphosphate, the introduction of orthophosphoric acid was considered, which along with inorganic acids and substances, decomposing at $100-250{ }^{\circ} \mathrm{C}$, additionally contributes to better coke formation, thereby showing the properties of antipyrene. The fire-retardant effect is mainly caused by a sharp change in the mechanism of thermal transformations of the carbohydrate part of the complex.

The presence of phosphoric acid changes the $\mathrm{CO} / \mathrm{CO}_{2}$ ratio in the direction of inhibition of direct oxidation of carbon in $\mathrm{CO}_{2}$, reducing to a large extent the exothermic effect of the process. By means of numerous laboratory mixes, the effective concentration of acid, $-1 \%$ by weight, has been selected. This amount does not have a negative impact on the physical and mechanical properties of the coating, and solves the problem of cratering in the formation of the coating by shifting the equilibrium of the system according to the principle of Le Châtelet-Brown in the direction of binding the molecules of ammonium polyphosphate due to additional phosphate ions, thereby preventing the release of ammonia.

However, when introducing any components into the paint formulation, it is necessary to assess their impact on the fire protection properties of the coating [19-23]. In order to assess the effect of orthophosphoric acid on the fire protection properties of the tested fireproof paint, a comparative thermal analysis was carried out. Two formulations were studied: without acid introduction and with $1 \%$ acid content by weight. A derivatograph device was used for the complex thermal analysis; it was the basis for the automated thermal analysis installation with the computer applications. Quantity of the substance- $0.05 \mathrm{~g}$; inert compound-aluminic oxide; atmosphere-air; temperature increase rate $-10{ }^{\circ} \mathrm{C} / \mathrm{min}$; temperature interval of the test $-20-950{ }^{\circ} \mathrm{C}$; and thermoscale sensitivity $-0.10 \mathrm{mg}$. In Figure $8 \mathrm{a}, \mathrm{b}$, the thermograms of the tested fireproof paint samples are presented, and in Tables 3 and 4 the conclusions on these graphs are given. 
Table 3. Physicochemical parameters of the fireproof paint samples with different PFA brands.

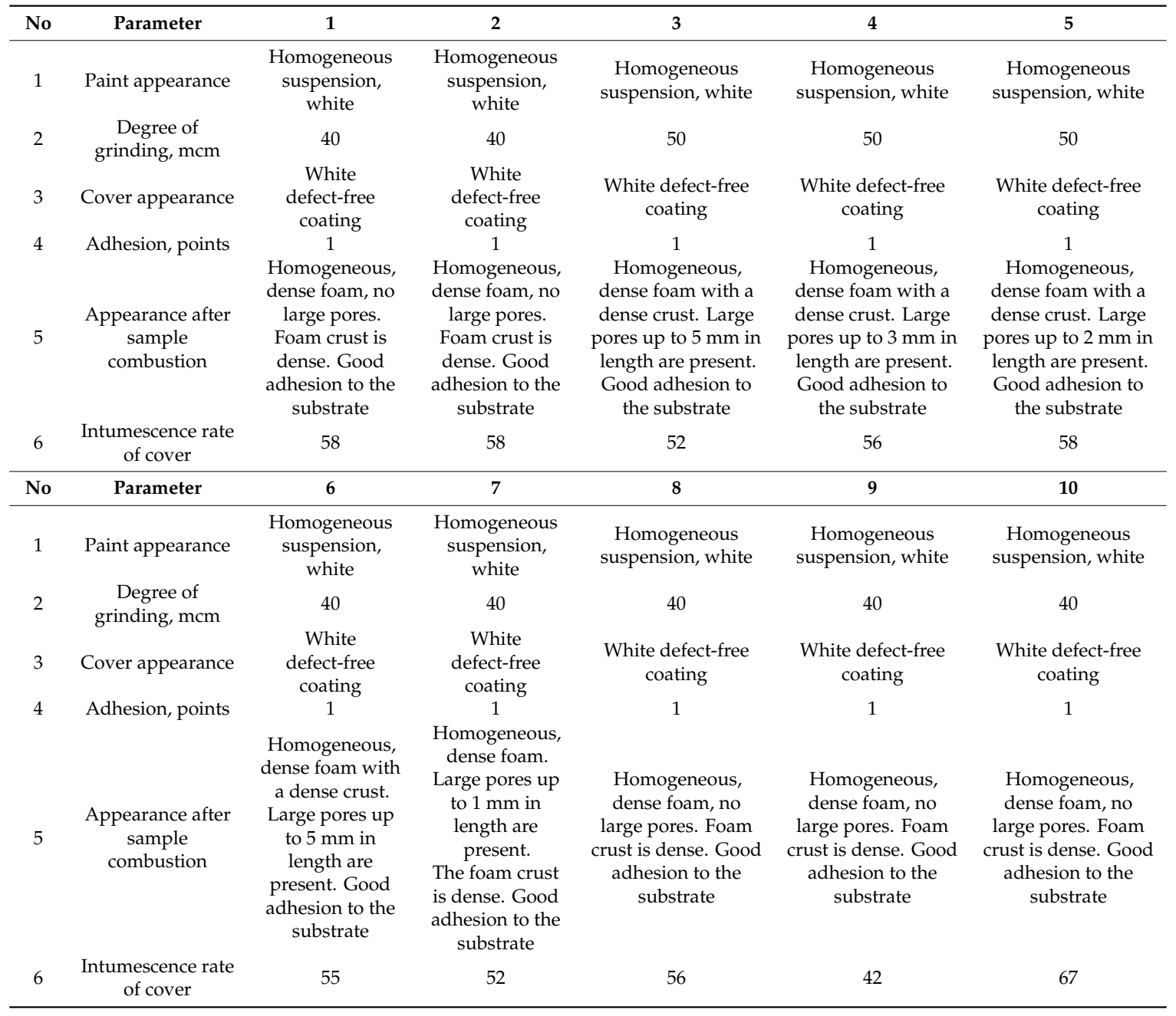

Table 4. Conclusions on the thermograms of the tested fireproof paint samples.

\begin{tabular}{|c|c|c|c|}
\hline No. & Thermal Effect & $\begin{array}{l}\text { Sample No. } 1 \\
\text { (Figure 8a) }\end{array}$ & $\begin{array}{l}\text { Sample No. } 2 \\
\text { (Figure } 8 \text { b) }\end{array}$ \\
\hline 1 & $\begin{array}{l}\text { In the temperature range under study (up to } 950{ }^{\circ} \mathrm{C} \text { ), } \\
\text { the sample begins to decompose at temperature, }{ }^{\circ} \mathrm{C}\end{array}$ & 361 & 380 \\
\hline \multirow{4}{*}{2} & Endothermic effect in the temperature range, ${ }^{\circ} \mathrm{C}$ & $(68-60)$ & $(86-380)$ \\
\hline & Temperatures at which $\quad$ Water removal, ${ }^{\circ} \mathrm{C}$. & 74 & 76 \\
\hline & $\begin{array}{c}\text { reaction rates are } \\
\text { maximum: }\end{array} \quad \begin{array}{c}\text { Start of decomposition of } \\
\text { antipyrenes at temperatures },{ }^{\circ} \mathrm{C} .\end{array}$ & $122,248,269345$ & $129,193,208,235$ \\
\hline & Temperatures of extremes, ${ }^{\circ} \mathrm{C}$. & 257,318 & $86,230,330$ \\
\hline \multirow{3}{*}{3} & Exothermic effect in the temperature range, ${ }^{\circ} \mathrm{C}$. & $(361-574)$ & $(380-678)$ \\
\hline & $\begin{array}{l}\text { Temperatures at which the reaction of antipyrene } \\
\text { decomposition takes place, }{ }^{\circ} \mathrm{C} \text {. }\end{array}$ & 390,429 & $397,487,565$ \\
\hline & Temperatures of extremes, ${ }^{\circ} \mathrm{C}$. & 485 & $380,565,616$ \\
\hline \multirow{3}{*}{4} & Exothermic effect in the temperature range, ${ }^{\circ} \mathrm{C}$. & $(574-950)$ & $(680-950)$ \\
\hline & $\begin{array}{l}\text { Temperatures at which the reaction of antipyrene } \\
\text { decomposition takes place }{ }^{\circ} \mathrm{C} \text {. }\end{array}$ & 610,844 & 842,658 \\
\hline & Temperature of extremes, ${ }^{\circ} \mathrm{C}$. & 874 & 871 \\
\hline
\end{tabular}




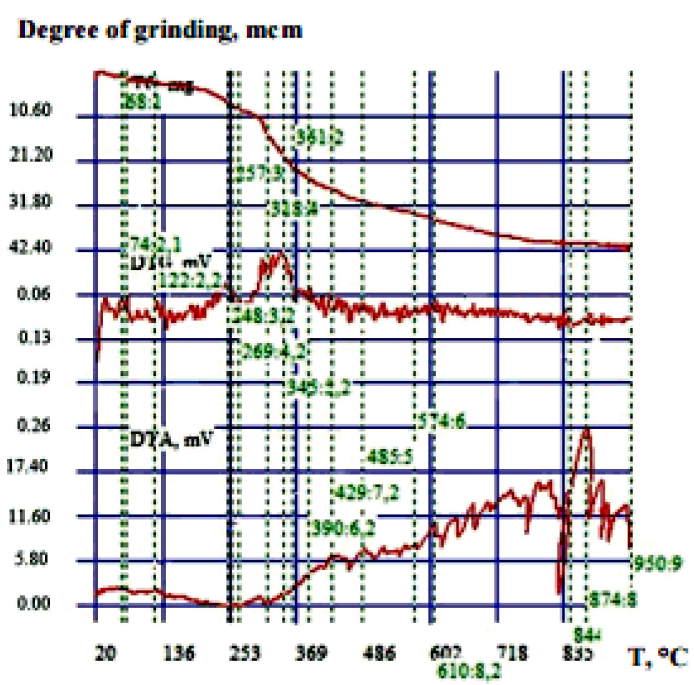

(a)

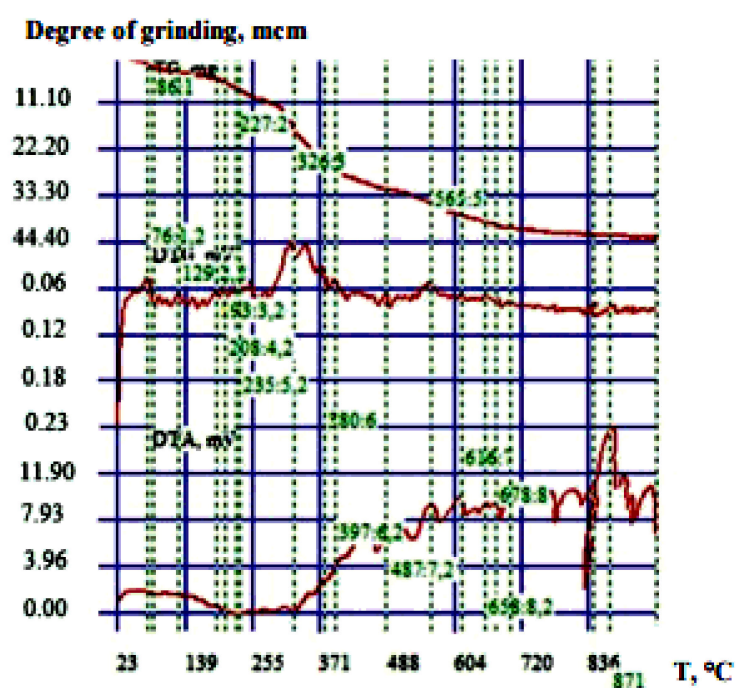

(b)

Figure 8. The thermograms: (a) paint sample without acid; (b) paint sample with $1 \%$ acid.

Further identification of samples was carried out using a mathematical analysis method. Based on GOST R 53293-2009, "Fire hazard of substances and materials. Materials, substances and means", it has been established that according to the results of the complex thermal analysis the samples are identical as the difference between the peak mean values did not exceed $30 \%$; the difference in the values of mass loss at fixed temperatures did not exceed $15 \%$; the difference in the values of temperatures of fixed mass loss did not exceed $15 \%$; the mean values of the identification characteristics of the thermal analysis of the samples fit into the confidence interval of similar identifier indexes.

\section{Results}

According to the analysis of the presented thermograms, it has been established that at the introduction of orthophosphoric acid into the composition there is a shift in peaks in the area of higher temperatures, which shows improvement in the fire protection properties.

After thermal analysis, the modified sample was subjected to full-scale fire testing. Comparative tests were carried out in accordance with GOST 30247.1-94 [24] and GOST R 53295-2009 [19], where metal structures were tested with and without load, respectively. Table 5 shows initial data and test results.

Table 5. Results of full-scale fire tests.

\begin{tabular}{|c|c|c|c|}
\hline No & Indicators & GOST 30247.1-94 [24] & GOST R 53295-2009 [19] \\
\hline 1 & $\begin{array}{c}\text { Description of } \\
\text { construction for testing }\end{array}$ & $\begin{array}{l}\text { A construction with a length of } \\
4300 \mathrm{~mm} \text {. On an unheated surface the } \\
\text { static concentrated load with total value } \\
(12.17 \pm 0.6) \mathrm{t} \text { was applied according to } \\
\text { the two-point scheme in each third of } \\
\text { the span length. }\end{array}$ & $\begin{array}{l}\text { A construction with a height of } \\
(1700 \pm 10) \mathrm{mm} \text {, (the given thickness of } \\
\text { metal } 5.8 \mathrm{~mm}) \text { without static load, } \\
\text { at quadruple thermal influence before } \\
\text { the limit state of the test sample. }\end{array}$ \\
\hline 2 & Conditions of the tests & $\begin{array}{l}\text { Ambient temperature- }-22.8^{\circ} \mathrm{C} \text {; } \\
\text { atmospheric pressure- } 102.4 \mathrm{kPa} \\
\text { relative humidity- } 43 \% .\end{array}$ & $\begin{array}{l}\text { Ambient temperature }-24.2^{\circ} \mathrm{C} \text {; } \\
\text { atmospheric pressure- } 100.1 \mathrm{kPa} \text {; } \\
\text { relative air humidity }-40 \% .\end{array}$ \\
\hline 3 & $\begin{array}{l}\text { Temperature regime, } \\
\text { p. p. } 6.1,6.2 \\
\text { GOST 30247.0-94 [25] }\end{array}$ & Within the norms. & Within the norms. \\
\hline 4 & $\begin{array}{l}\text { Loss of bearing capacity } \\
\qquad(\mathrm{R})\end{array}$ & $\begin{array}{l}90 \text { min after the start of the load-bearing } \\
\text { capacity test, the load-bearing capacity } \\
\text { limit has not been reached. }\end{array}$ & $\begin{array}{l}90 \text { min after the start of the load-bearing } \\
\text { capacity test, the load-bearing capacity } \\
\text { limit has not been reached. }\end{array}$ \\
\hline
\end{tabular}


Figure 9a,b and Figure 10a,b show the graphic dependencies characterizing the test mode and the behavior of the structure with fire protection during the test. Based on the data presented, it can be concluded that the tested fire protection paint sample is a reliable flame retardant under various test conditions.

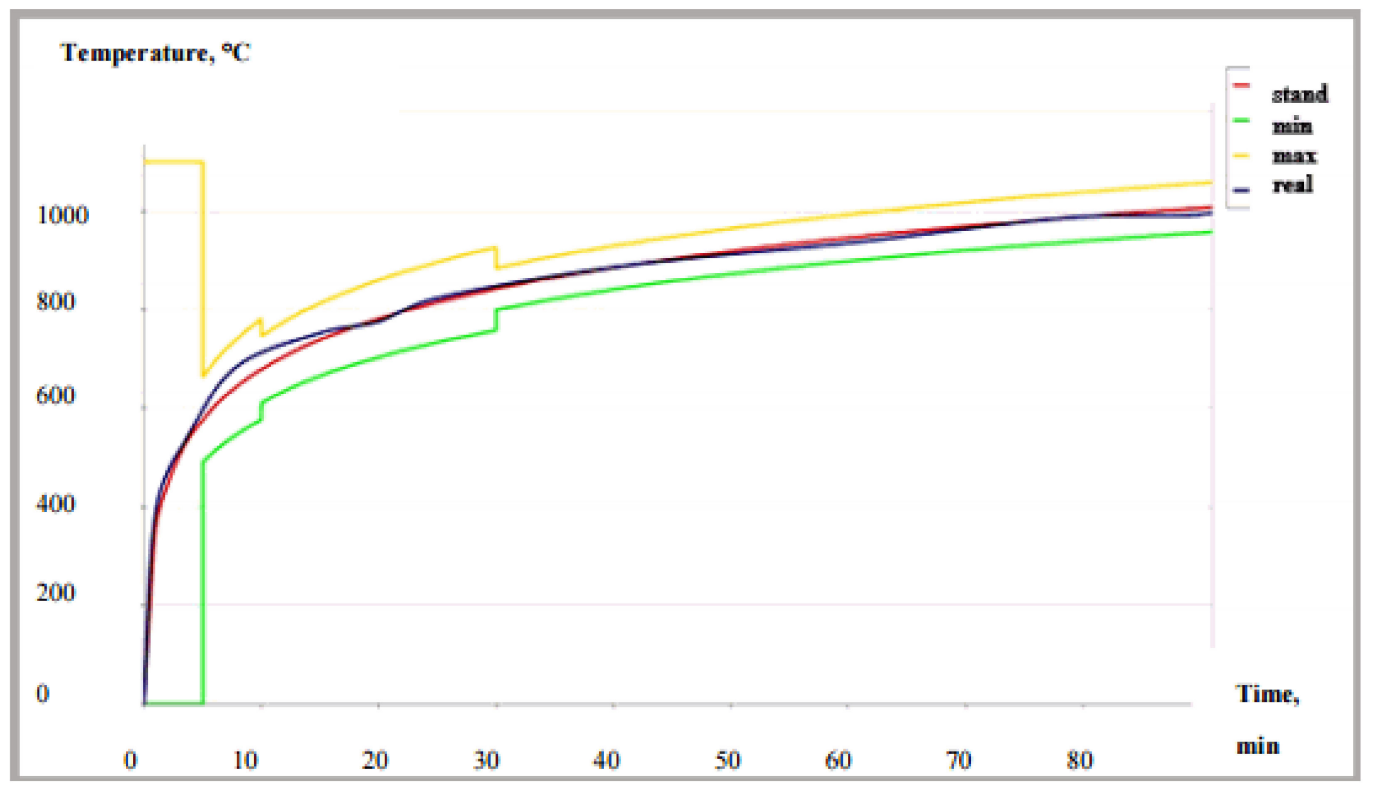

(a)

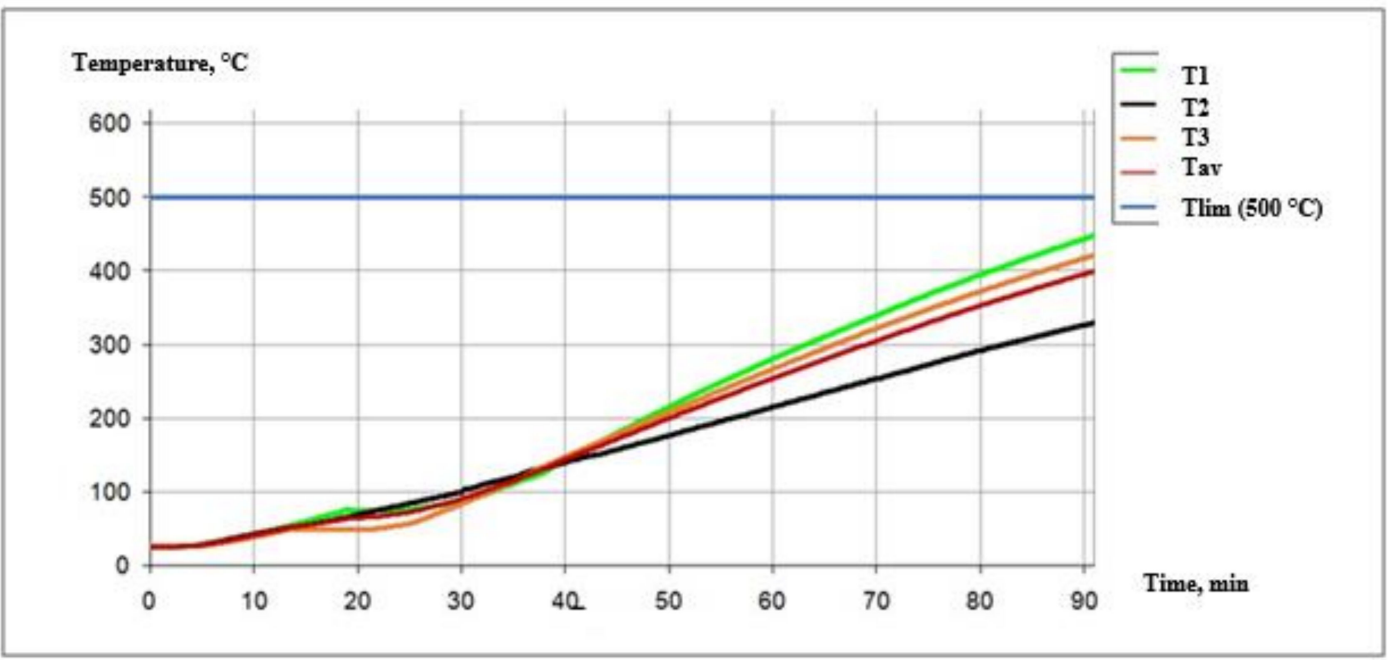

(b)

Figure 9. (a) The temperature regime of the tests GOST 30247.1-94 [24]. (b) Structure heating during the test according to GOST 30247.1-94 [24]. 


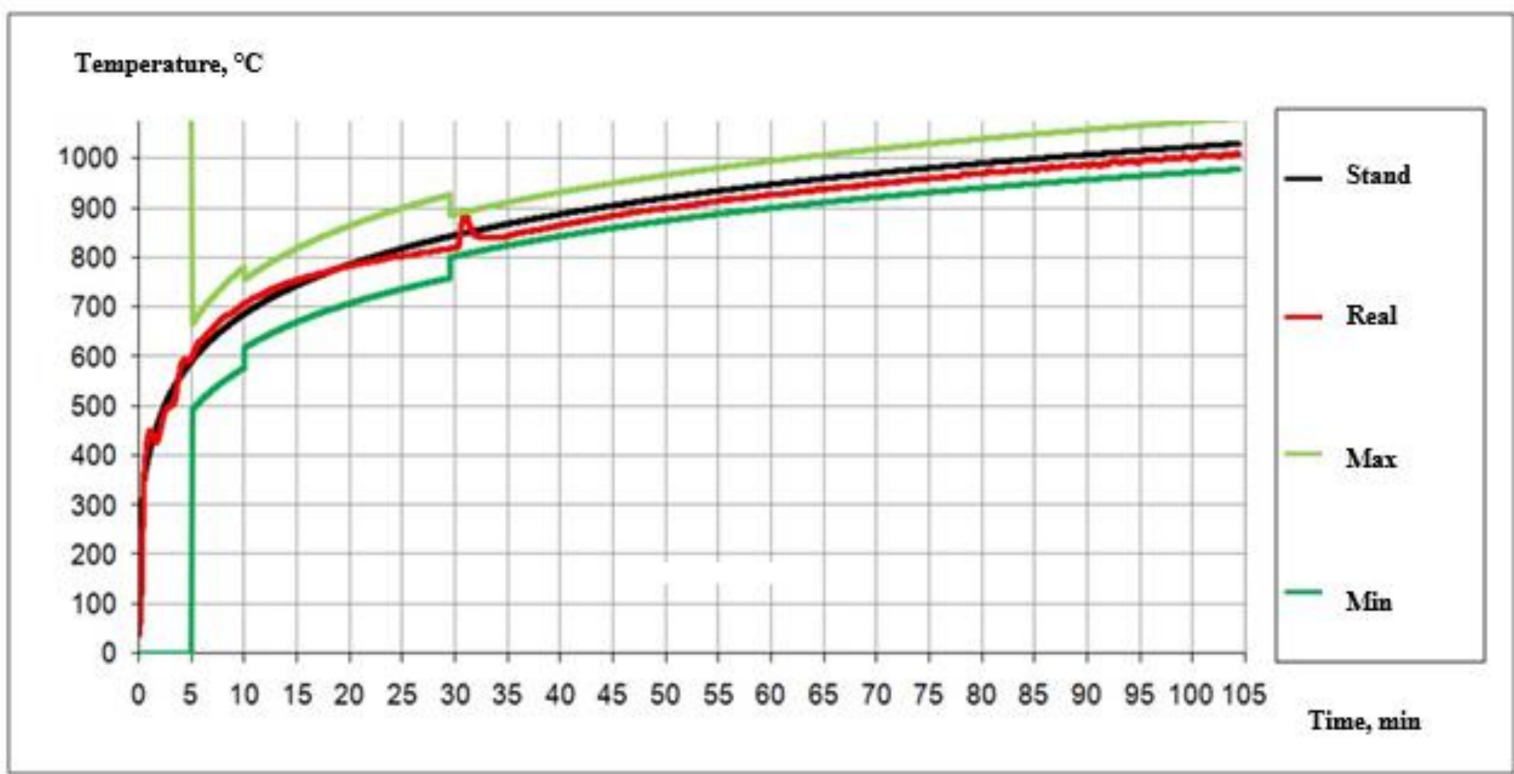

(a)

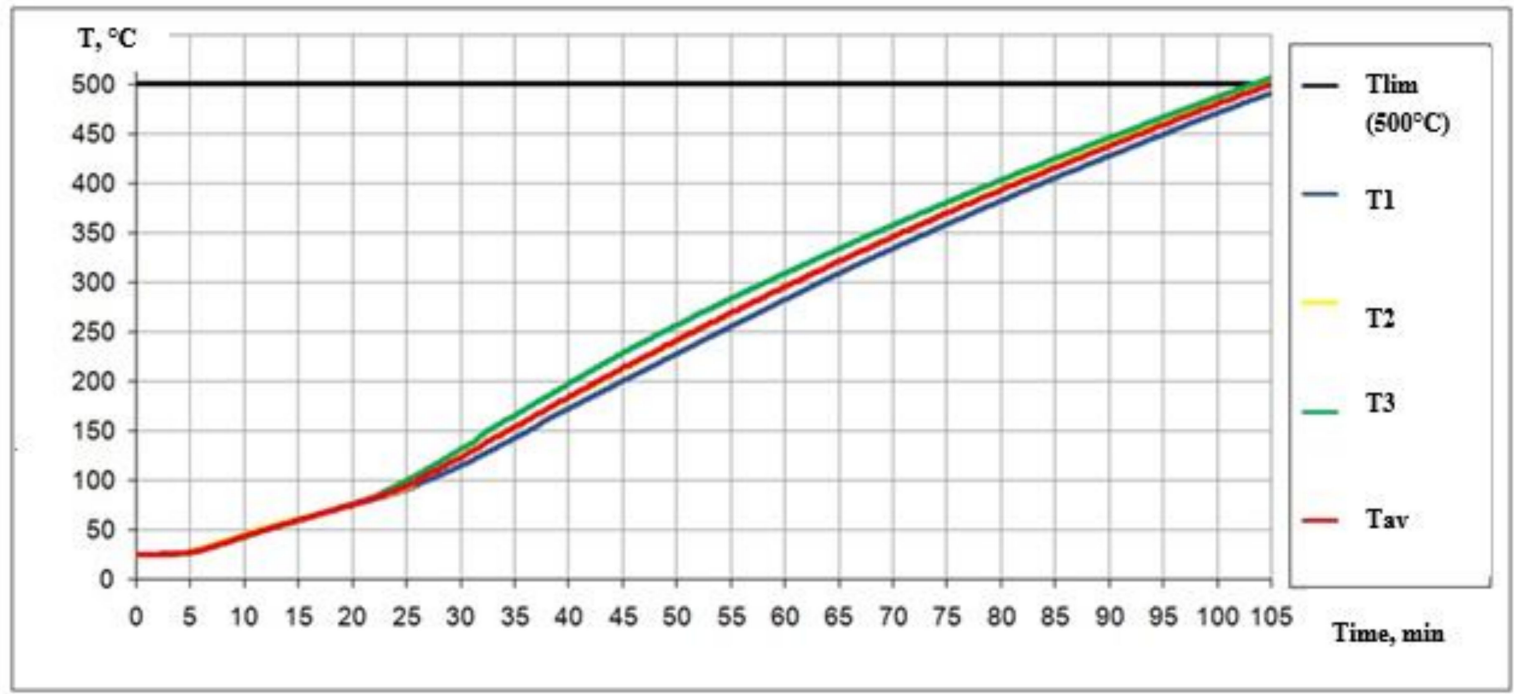

(b)

Figure 10. (a) Temperature regime of the test according to GOST R 53295-2009 [19]. (b) Structure of heating during the test according to GOST 53295-2009 [19].

Summarizing the obtained data on the thermal analysis of the fire protection paint and the data of the full-scale fire tests, we can conclude that the preliminary thermal analysis gives the results of the physical and chemical processes and their impact on the fire protection efficiency in general. The preliminary thermal analysis of a fire protection paint helps to quickly assess its flame-retardant properties and helps predict its behavior in large-scale field fire tests [26].

\section{Conclusions}

Fire protection of building constructions, taking into account their fire resistance limit, is based on the properties of fire-retardant intumescent compositions. The physical and chemical properties of intumescent fire protection paints have a direct impact on the flame-retardant properties of the 
composition. The set of these properties is determined by the components of the formulation and their work as a whole. The conducted research on the influence of several components of the formulation of the tested intumescent fire protection paint shows the importance and necessity of this type of work for complete and qualitative evaluation of the fire protection properties, in order to obtain reliable and effective compositions for the fire protection. The presented research methods are indicative and effective in investigating the influence of the formulation's components on the effectiveness of the fire-retardant intumescent paints. These types of studies can be the basis for both the development of new flame retardants and testing of existing formulations, including comparative analyses. These methods of thermal analyses can also be used for testing formulations of non-intumescent flame retardants, in order to obtain primary data on the thermal transitions in case of heating.

Author Contributions: Conceptualization, T.E. and D.K.; methodology, T.E.; software D.K.; validation, T.E. and D.K.; formal analysis, T.E.; investigation, D.K.; resources, D.K.; data curation, T.E.; writing-original draft preparation, T.E. writing-review and editing, D.K.; visualization, T.E.; supervision, D.K.; project administration, D.K.; funding acquisition, T.E. All authors have read and agreed to the published version of the manuscript.

Funding: This work was financially supported by the Ministry of Science and Higher Education of the Russian Federation (Project: Theoretical and experimental design of new composite materials to ensure safety during the operation of buildings and structures under conditions of technogenic and biogenic threats \#FSWG-2020-0007).

Conflicts of Interest: The authors declare no conflict of interest. The funders had no role in the design of the study; in the collection, analyses, or interpretation of data; in the writing of the manuscript, or in the decision to publish the results.

\section{References}

1. Edward, D. Wail. Fire-Protective and Flame-Retardant Coating. J. Fire Sci. 2011, 29, 259-296.

2. Oliveira, R.B.; Moreno Junior, A.L.; Vieira, L.C. Intumescent paint as fire protection coating. Struct. Mater. J. 2017, 10, 220-231. [CrossRef]

3. Horrocks, A.R.; Price, D. Fire Retardant Materials; Woodhead Publishing Limited: Cambridge, UK, 2001; p. 442.

4. Korolchenko, D.; Eremina, T.; Minailov, D. New Method for Quality Control of Fire Protective Coatings. In Proceedings of the IAPE ‘19 Conference, Oxford, UK, 14-15 March 2019.

5. Eremina, T.; Konstantinova, N.; Kuznetsova, I. Study of fireproof properties of textile materials safe when in contact with human skin. In Proceedings of the Conference Construction the Formation of Living Environment (FORM-2019), Tashkent, Uzbekistan, 18-21 April 2019.

6. Konstantinova, N.I.; Eremina, T.Y.; Kuznetsova, I.N. Development of fireproof textile materials safe on contact with human skin. Fibre Chem. 2019, 51, 131-134. [CrossRef]

7. Konstantinova, N.; Eremina, T.; Kuznetsova, I. Development of fire-proof textile materials safe for human skin. Chem. Fibres 2019, 2, 54-57.

8. Eremina, T.; Gravit, M.; Dmitrieva, Y. Aspects and principles of formulation development for flame retardant intumescent compositions based on epoxy resins. Fire Explos. Saf. 2012, 7, 52-56.

9. Zybina, O.; Babkin, O. On the formulation of effective fire retardant paints and varnishes for building structures. Paint. Varn. Their Appl. 2018, 3, 44-47.

10. Wang, J.Q.; Chow, W.K. A brief review on fire retardants for polymeric foams. J. Appl. Polym. Sci. 2005, 97, 366-376. [CrossRef]

11. Zybina, O.A.; Varlamov, A.V.; Chernova, N.S.; Mnatsakanov, S.S. On the role and transformations of components of intumescent fire-retardant paint-and-varnish formulations in the course of thermolysis. Russ. J. Appl. Chem. 2009, 82, 1542-1546. [CrossRef]

12. Khalturinsky, N.; Krupkin, V. On the mechanism of action of fire retardant intumescent coatings. Fire Explos. Saf. 2011, 10, 33-41.

13. Ruban, L.; Zaikov, G. Importance of intumescence in polymers fire retardancy. Int. J. Polym. Mater. 2001, 48, 295-310. [CrossRef]

14. Eremina, T. Modeling and evaluation of fire retardant efficiency of intumescent flame retardants. Fire Explos. Saf. 2003, 12, 22. 
15. Suzuki, J.; Mizukami, T.; Naruse, T.; Araki, Y. Fire Resistance of Timber Panel Structures Under Standard Fire Exposure. Fire Tech. 2019, 4, 1015-1034. [CrossRef]

16. Bezzaponnaya, O.; Golovina, E.; Mansurov, T.; Akulov, A. The use of thermal analysis method for the comprehensive study and improvement of intumescent fire retardants. Technosphere Saf. 2017, 2, 3-7.

17. Eremina, T.; Yushko, E.; Nikolaeva, E. The influence of phosphoric acid on the reduction of crater formation of water-borne fire retardant intumescent paint. Paint. Varn. Their Use 2015, 3, 40-42.

18. Eremina, T.; Korolchenko, D.; Kuznetsova, I.; Features of Properties of the Fireproof Paint during the Operation. WMCAUS-2019. Available online: https://www.wmcaus.org/files/WMCAUS2019_Book.pdf (accessed on 7 September 2020).

19. GOST R 53293-2009. Fire Hazard of Substances and Materials, Materials, Substances and Means. Available online: https://runorm.com/catalog/102/828617/ (accessed on 7 September 2020).

20. Zav'Yalov, D.E.; Zybina, O.A.; Mitrofanov, V.V.; Mnatsakanov, S.S. Comparative study of the behavior of ammonium phosphate in fireproofing intumescent formulations. Russ. J. Appl. Chem. 2012, 85, 1070-4272. [CrossRef]

21. Zav'yalov, D.E.; Zybina, O.A.; Chernova, N.S.; Varlamov, A.V.; Mnatsakanov, S.S. Fire intumescent compositions based on the intercalated graphite. Russ. J. Appl. Chem. 2010, 83, 1679-1682. [CrossRef]

22. Ustinov, A.; Zybina, O.; Tanklevsky, L.; Lebedev, V.; Andreev, A. Intumescent coatings with improved properties for high-rise construction. E3S Web Conf. 2018, 33, 02039. [CrossRef]

23. Ustinov, A.; Zybina, O.; Tomakhova, A.; Pavlov, S. The enhancement of operating properties of intumescent fire-protective compositions. MATEC Web Conf. 2018, 245, 11008. [CrossRef]

24. GOST R 30247.1-94. Elements of building constructions. Fire-Resistance Test Methods. Loadbearing and Separating Constructions. Available online: https://www.russiangost.com/p-16532-gost-302471-94.aspx (accessed on 7 September 2020).

25. GOST R 30247.0-94. Elements of building constructions. Fire-resistance test methods. General requirements. Available online: https://www.russiangost.com/p-17524-gost-302470-94.aspx (accessed on 7 September 2020).

26. Ustinov, A.A.; Zybina, O.A.; Andreev, A.V. On the impact caused by titanium dioxide of different trademarks on the properties of Intumescent fire-protective coatings. Mater. Sci. Forum 2019, 945, 212-217. [CrossRef]

Publisher's Note: MDPI stays neutral with regard to jurisdictional claims in published maps and institutional affiliations.

(C) 2020 by the authors. Licensee MDPI, Basel, Switzerland. This article is an open access article distributed under the terms and conditions of the Creative Commons Attribution (CC BY) license (http://creativecommons.org/licenses/by/4.0/). 